NASA Technical Memorandum 83610

\title{
Analysis of Stress-Strain, Fracture and Ductility Behavior of Aluminum Matrix Composites Containing Discontinuous Silicon Carbide Reinforcement
}

David L. McDanels

Lewis Research Center

Cleveland, Ohio

Prepared for the

One hundred thirteenth Annual Meeting of the American Institute of Mining, Metallurgical and Petroleum Engineers

Los Angeles, California, February 26-March 2, 1984 
ANALYSIS OF STRESS-STRAIN, FRACTURE AND DUCTILITY BEHAVIOR OF ALUMINUM MATRIX

COMPOSITES CONTAINING DISCONTINUOUS SILICON CARBIDE REINFORCEMENT

\author{
David L. McDanels \\ National Aeronautics and Space Administration \\ Lewis Research Center \\ Cleveland, Ohio 44135
}

\begin{abstract}
SUMMARY
Mechanical properties and stress-strain behavior were evaluated for several types of commercially fabricated aluminum matrix composites, containing up to 40 vol \% discontinuous Sic whisker, nodule, or particulate reinforcement. The elastic modulus of the composites was found to be isotropic, to be independent of type of reinforcement, and to be controlled solely by the volume percentage of SiC reinforcement present. The yield/tensile strengths and ductility were controlled primarily by the matrix alloy and temper condition. Type and orientation of reinforcement had some effect on the strengths of composites, but only for those in which the whisker reinforcement was highly oriented. Ductility decreased with increasing reinforcement content, however the fracture strains observed were higher than those reported in the literature for this type of composite. This increase in fracture strain was attributed to cleaner matrix powder and increased mechanical working during fabrication. Comparison of properties with conventional aluminum and titanium structural alloys showed that the properties of these low-cost, lightweight composites demonstrated very good potential for application to aerospace structures.
\end{abstract}

\title{
INTRODUCTION
}

The majority of effort in aluminum matrix composites has been directed toward development of high performance composites, with very high strengths and moduli, for use in specialized aerospace applications. However, there are a number of other applications in aircraft engines and aerospace structures where these very high properties may not be required, and where it could be cost effective to use other metal matrix composites. For example, cost-, weight- and stiffness-critical components, such as engine static structures, do not require the very high directional properties available with composites reinforced with aligned continuous fibers. Replacement of such current aluminum, titanium, or steel structures by low cost composites offers the potential of significant weight and cost savings.

For these reasons, efforts were initiated to assess the potential of applying low cost aluminum matrix composites to these structures, using low cost reinforcements and low cost composite fabrication processes, including powder metallurgy, direct casting and hot molding techniques (ref. 1). As part of this assessment, panels of aluminum matrix composites containing discontinuous silicon carbide whisker $\left(S_{i} C_{w}\right)$, nodule $\left(S i C_{n}\right)$, or particulate $\left(S i C_{p}\right)$ reinforcement were fabricated under contract and delivered to NASA Lewis for evaluation. 
Results from preliminary mechanical property testing of these Sic/Al composites ( $r e f .1$ ) indicated that they had significantly higher elastic moduli than conventional aluminum alloys and deserved further evaluation. Stressstrain and fracture results, with particular emphasis on modulus, strength, ductility and microstructure, were reported in reference 2 . It is the purpose of this current paper to analyze these results in terms of the principal factors influencing the stress-strain behavior and mechanical properties of this type of SiC/Al composite.

\section{MATERIALS}

Three types of aluminum matrix composites containing discontinuous SiC reinforcement have recently become commercially available and were studied in our investigations. Two types, containing SiC reinforcements produced from rice hulls (ref. 3), are being produced by ARCO Metals (formerly Silag Div. of Exxon Corp.). These composites contained either a predominately SiC whisker reinforcement (Type $F-9$, nominal mixture of 80 percent whiskers/20 percent nodules) or a predominately SiC nodule reinforcement (Type $X-0$, nominal mixture of 80 percent nodules/20 percent whiskers). A third type of aluminum matrix composite containing discontinuous SiC particulate reinforcement is being produced by DWA Composite Speciaities, Inc. This type of composite is made with reinforcement obtained from single crystals of abrasive-grade SiC that have been crushed into fine powder and separated by size (ref. 4).

Similar methods were used to fabricate composites containing each type of SiC reinforcement (refs. 4 and 5). In each case, the Sic reinforcement was blended with aluminum alloy powder, compacted into billets and sintered. The sintered billets were extruded and then cross-rolled into $2.54 \mathrm{~mm}$ thick flat plates. Composites containing 6061, 2024/2124, 7075 or 5083 A1 matrices were fabricated in this manner and delivered to NASA Lewis for evaluation.

The microstructure of each type of SiC/Al composite was examined by heavily etching the surfaces with $\mathrm{HCl}$ to remove some of the aluminum matrix to expose the SiC reinforcement distribution below the original surface. Scanning electron microscope (SEM) photographs (fig. 1) show the structure of a typical $\mathrm{SiC}_{\mathrm{W}} / 6061 \mathrm{Al}$ composite and indicates that three types of particles are present: whiskers, nodules, and agglomerates. The equiaxed acicular whiskers were hexagonal in cross section and ranged in width from 0.2 to $0.9 \mu \mathrm{m}$. The whiskers tended to have a general orientation perpendicular to the final rolling direction, and parallel to the extrusion direction. Some nodule reinforcement and ribbon-like whiskers were also observed. Areas of differential etching were also observed, indicating either a difference in chemical composition or in internal strain energy states. It is probable that these areas are unstringered agglomerated matrix particles, since the less heavily worked areas of the composite would tend to be less anodic, and thus would etch at a slower rate than the more anodic, more heavily worked regions.

Figure 2 shows the structure of a typical $\mathrm{SiC}_{n} / 6061 \mathrm{Al}$ composite and indicates that the reinforcement primarily consists of SiC nodules. These nodules were irregularly shaped platelets, 1 to $5 \mu \mathrm{m}$ in width, and tended to be equiaxed in cross section. A few whiskers were also visible, again having a generally transverse orientation. In addition, some agglomerated areas were also visible. 
Figure 3 shows the structure of a typical $\mathrm{SiC}_{\mathrm{p}} / 6061 \mathrm{Al}$ composite and indicates that the $\mathrm{SiC}_{\mathrm{p}}$ reinforcement is very angular and tends to have an irregularly jagged wedge shape. Most of the $\mathrm{SiC}_{\mathrm{p}}$ reinforcement tended to be 2 to $7 \mathrm{\mu m}$ in width, although 40 vol \% SiC $/ 6061$ Al composites showed a larger SiC particulate size, ranging up to 10 by $21 \mu \mathrm{m}$ across the ir extreme axes.

Tensile tests were used to evaluate the stress-strain behavior and me-chanical properties of the composites and to relate the effects of the type of Sic reinforcement, Sic reinforcement content, matrix alloy and temper condition on the properties of the composites, in both the longitudinal and transverse directions. Composites with 2024/2124, 6061 and 7075 Al matrices were tested in both the as-fabricated ( $F$-temper) and the heat-treated (T6-temper) cond $i$ tion, using heat treatments based upon those given in reference 6 . Composites with a 5083 Al matrix were tested in the F-temper only.

\section{RESULTS AND DISCUSSION}

\section{Factors Influencing Modulus of Elasticity}

The modulus of elasticity of 6061 Al matrix composites increased with increasing reinforcement content (fig. 4). Results from tests on the other Al matrices studied followed these same trends. This increase, however, was not linear, as in the case of composites with continuous fibers aligned in the testing direction. The modulus of the composites was below that expected from isostrain-type rule-of-mixtures behavior, and tended to approach an isostresstype hyperbolic function with reinforcement content, similar to that observed for transverse modulus behavior of continuous fiber composites.

The reinforcement content was the dominant factor in the improvement of modulus of elasticity in these SiC/Al composites. For a given reinforcement content, the modulus tended to be isotropic, with nearly equal values obtained from tests in both the longitudinal and transverse directions. In addition, the modulus appeared to be independent of type of reinforcement, with modulus values being within 5 percent of the average value for all composites tested at any given reinforcement content, regardless of type of reinforcement.

The modulus of the composites was also independent of the matrix alloy. Heat treatment of the composites may have had a slight effect on modulus. The modulus of composite in the T6-temper appeared to be slightly lower than the modulus measured on composites in the as-fabricated F-temper. This reduction was slight (about 3 to 4 percent) and was not consistent among all the matrix alloys tested, and may have been due to scatter in the data.

\section{Factors Influencing Strength}

The factors influencing the yield and tensile strengths of $\mathrm{SiC} / \mathrm{Al}$ composites are complex and interrelated, and the best way to evaluate this behavior is through isolation of variables and analysis of stress-strain curves and fracture behavior. 
Effect of Al matrix alloy. - The Al matrix used for the SiC/Al composites was the most important factor affecting yield strength and ultimate tensile strength of these SiC/AI composites. Stress-strain behavior is summarized in figure 5 , with the other parameters held constant. In this case 20 vol $\% \mathrm{SiC}_{\mathrm{W}}$ reinforcement, T6-temper (where applicable) and testing in the longitudinal direction were used as the analysis conditions. These curves show that SiC/Al composites with higher strength aluminum matrix alloys, such as $2024 / 2124$ or $7075 \mathrm{Al}$, had higher strengths but lower ductilities. Composites with a 6061 Al matrix showed good strength and higher ductility. Composites with a 5083 Al matrix failed in a brittle manner, with untimate strength related to failure strain. The $5083 \mathrm{Al}$ alloy is not heat-treatable and has been optimized to gain maximum properties by solid solution stengthening in the strain-hardened Htemper. The addition of the SiC reinforcement probably overstrained the lattice and thus the alloy no longer had sufficient strain energy remaining to gain its potential strength and ductility.

While heat treatment had little, if any, effect of the modulus of elasticity of the composites, it did affect the transition into plastic flow. Composites in the F-temper strained elastically and then passed into a normal decreasing-slope plastic flow. Composites tested in the T6-temper exhibited a slightly greater amount of elastic strain, with the elastic proportional limit being increased from about 0.10 to 0.15 percent strain to about 0.15 to 0.25 percent, but the greater influence was a steepening of the slope of the stressstrain curve at the inception of plastic flow, relative to that observed for composites in the F-temper. The inception of plastic flow was marked by a continuation of a slope that, while no longer elastic and starting to become plastic, approached that of the elastic portion. This slope decreased with increasing strain, until eventually reaching normal plastic flow leading to fracture at the uitimate tensile strength.

This increase in elastic proportional strain limit and steepening of the stress-strain curve were reflected by the higher yield and ultimate tensile strengths observed in the heat-treated composites. The increase in flow stress of composites with each heat-treatable matrix probably indicated the additive effects of dislocation interaction with both the natural alloy precipitates and the synthetic Sic reinforcement. The combination increased the lattice strain in the matrix, causing greater dislocation tangling and requiring higher flow stresses for deformation, resulting in the higher strengths observed.

The effects of matrix alloy and heat treatment on the ultimate tensile strength of SiC/Al composites, in both the $F$ and $T 6$ tempers, are summarized in figure 6 . The properties for the unreinforced matrix alloys were taken from the values for maximum strength tempers listed in reference 6 . The results showed that the yield and ultimate tensile strengths of the SiC/Al composites, with other parameters being constant, were primarily controlled by the intrinsic yield/tensile strengths of the matrix alloys. These results also showed that, in general, the yield and ultimate tensile strengths of the composites, with 20 vol \% SiC ${ }_{W}$ reinforcement, were higher than those of the same heat treated matrix alloys without reinforcement. The same trends of increased yield/tensile strengths were also observed for composites with these matrices using other types of SiC reinforcement and at other reinforcement contents. The largest increase in yield/tensile strengths over the unreinforced matrix alloy, was achieved by the SiC/6061 Al composites. 
Effect of reinforcement content. - Reinforcement content is another important factor controlling the strength of $\mathrm{SiC} / \mathrm{Al}$ composites. The effect of reinforcement content of a given type of SiC reinforcement, is shown in the yield/ultimate tensile strength histograms in figure 7 for each alloy, tested in the T6-temper if applicable. The data shown are the range of results of all tests conducted in both the longitudinal and transverse testing direction, with the average value from each testing direction indicated by the " $L$ " and " $T$ " ticks. These figures show that, for a given matrix alloy and reinforcement, the yield and ultimate tensile strengths generally increased with increasing reinforcement content.

Part of the explanation for the strength increase observed can be seen from the stress-strain curves for SiC/6061 Al composites containing different reinforcement types and contents (fig. 8). These curves show that the proportional limit stress, where the composite entered plastic flow, increased as the reinforcement content was increased, for each alloy tested. As the reinforcement content was increased, the elastic modulus increased and caused the stress-strain curves to enter plastic flow at a higher flow stress. The slope of the stress-strain curve also increased as the composite entered plastic flow, and a higher flow stress was required to reach a given plastic strain until either a stable plastic flow was reached (ductile failure) or the specimen failed (brittle failure). This indicated that the strength increase was probably caused by closer packing of the reinforcement and smaller interparticle spacing in the matrix. This would cause increased interaction of dislocations with the SiC reinforcement, resulting in increased strain-hardening.

The strength increased with increasing reinforcement content only as long as the composite was able to exhibit enough ductility to attain full strength. As the content reached 30 to 40 vol \% SiC, the strength increase tended to taper off because the composites failed while still in the steeply ascending portion of the stress-strain curve. In this region, the matrix probably did not have sufficient internal ductility to redistribute the very high localized internal stresses and the composites failed before being able to reach stable plastic flow and normal ultimate strength.

Effect of reinforcement type and directionality. - Composites containing acicular $\mathrm{SiC}_{w}$, irregular equiaxed $\mathrm{SiC}_{n}$, or irregular jagged $\mathrm{SiC}_{\mathrm{p}}$ reinforcements were studied in this investigation. Stress-strain curves for $6061 \mathrm{Al}$ matrix composites with 20 vol \% of various SiC reinforcements indicated that the yield and ultimate tensile strengths of the $S_{i C}$ and $S_{i C}$ reinforcements were similar, while composites with $\mathrm{SiC}_{n}$ reinforcements were about 10 percent lower in yield and ultimate tensile strengths (fig. 8). No significant effect of directionality on strength properties was observed with 6061 Al matrix composites for any of the SiC reinforcements at contents from 10 to $40 \mathrm{vol} \%$.

The orientation of the $\mathrm{SiC}_{\mathrm{w}}$ reinforcement in all matrices was generally in the transverse direction indicating that the whisker orientation was established during the initial extrusion phase of fabrication. The composites were then cross rolled normal to the extrusion direction, but the cross rolling did not appear to change the original whisker orientation and thus the whisker alignment tended to be perpendicular to the final rolling direction.

Some orientational differences were observed in composites with $\mathrm{SiC}_{W} / \mathrm{Al}$ composites. Normally, any differences in yield strength with orientation were 
minor (fig. $7(\mathrm{a})$ ), although significant differences were observed in ultimate tensile strength in 7075 and $2124 \mathrm{Al}$ matrices (fig. 7(b)). In these cases, with 20 vol $\% \mathrm{SiC}_{\mathrm{W}}$ reinforcement, the yield and ultimate tensile strengths of the T6-temper composites were about 20 percent higher when tested in the transverse direction, compared to the longitudinal ( $f$ ig. 9). Etched surfaces of these composites (fig. 10(a)) showed a greater degree of preferred whisker orientation than that of the 6061 Al matrix composites ( $f$ ig. 1 ).

Comparison of the microstructure of the fracture surfaces of the 20 vol \% $\mathrm{SiC}_{\mathrm{W}} / 7075 \mathrm{Al}$ composites showed different behavior for specimens tested in the longitudinal and transverse directions. The 7075 Al matrix composites had an ultimate tensile strength of $648 \mathrm{MPa}(94.0 \mathrm{ksi})$ in the transverse direction, but only $542 \mathrm{MPa}(78.6 \mathrm{ksi})$ in the longitudinal direction. The fracture surface (fig. 10(b)) of the transverse specimens show that many more whiskers are projecting out of the surface of the composite specimen than were observed in similar specimens tested in the longitudinal direction or in the $6061 \mathrm{Al}$ composites. Similar trends were observed in the transverse fracture surfaces of the 20 vol $\%$ SiC $_{W} / 2124$ Al composites.

It appeared that where directional strengthening did occur with $\mathrm{SiC}_{\mathrm{W}}$ reinforcement, the fracture surface indicated protruding whiskers (7075 and $2124 \mathrm{~A} 1$ ) with the whisker base still adherent to the matrix and no crater found at the base. In cases where no directionality was observed (6061 and $5083 \mathrm{Al}$ ), the matrix appeared to have pulled away from the whisker and formed a crater, possibly fracturing the whisker, but more probably establishing a fracture path through the matrix just beyond the ends of the whiskers. In both situations however, no matrix appeared to be adhering to the exposed whiskers, and therefore, it appeared that the whiskers merely pulled out of the matrix through interfacial shear. If shear pull-out occurred, it would be improbable that the whiskers failed in tension and thus the full strengthening potential of the whiskers was not realized.

The tensile properties of all the composites with $\mathrm{SiC}_{\mathrm{W}}$ reinforcement tested in the longitudinal direction, regardless of the Al matrix, appear to have strengths fairly comparable with those of composites with the equiaxed $\mathrm{SiC}_{\mathrm{p}}$ and $\mathrm{SiC}_{\mathrm{n}}$ reinforcements. While some strength increases were observed in the direction of the reinforcement orientation for the $\mathrm{SiC}_{W} / \mathrm{Al}$ composites, the effect was not universal. Since the modulus and the yield/tensile strength values for the $S_{i} C_{W} / A l$ composites were comparable to those of the $S i C_{n}$ and $\mathrm{SiC}_{\mathrm{p}}$ composites, in all cases in the direction perpendicular to the $\mathrm{SiC}_{\mathrm{W}}$ reinforcement, and in some cases parallel to the reinforcement, then it appears that, at the current state of the art, the reinforcing process in these composites tends to be more of a dispersoid strengthener than a fiber strengthener. With the current state of the art of SiC reinforcement production and composite fabrication, it may be more beneficial to consider all Sic/Al composites, regardless of reinforcement type, as a single class of isotropic materials and to utilize their commonality with conventional aluminum alloys as a major advantage, allowing established aluminum component design to be used, and allowing conventional aluminum metalworking and forming processes to be used.

With further development, the $\mathrm{SiC}_{W} / \mathrm{Al}$ composites may prove more advantageous for specialized applications. However, for whisker reinforcement to be effective, assuming adequate bonding and sufficient whisker length, the 
whiskers must be preferentially oriented within a few degrees of the loading axis and the whisker surface must remain perfect. The fabrication processes used to produce $S_{i} C_{W} / A l$ composites inherently sets up conditions that work against effective utilization of full whisker properties in these composites. First, in the reinforcement/powder blending process, the whisker surfaces will probably become flawed and their intrinsic, as-produced strength and aspect ratio will be reduced. Second, the extrusion of the sintered SiC/Al billets will cause further breaking up of the whiskers and further flawing of their surfaces. In addition, conventional extrusion can, at best, give only a partial orientation of the $S_{i} C_{W}$ reinforcement.

\section{Factors Influencing Ductility}

Ductility of SiC/Al composites, as measured by strain to failure, is again a complex interaction of parameters. However, the prime factors affecting these properties are reinforcement content, matrix alloy, and orientation.

With increasing reinforcement content, the failure strain of the composites is reduced and the stress-strain curves also reflect a change in the fracture mode. Failure strains for the various composites tested are plotted in figure 11 (a) as a function of reinforcement content for 6061 Al matrix composites for both the F- and T6-tempers. Figure $11(b)$ shows a similar plot for the other Al matrix alloys tested in their optimized temper. Photographs of the fracture modes observed are shown in figure 12.

Preliminary tensile tests, conducted on wrought aluminum specimens with no sic reinforcement, exhibited failure strains of about 15 percent, with a smooth $45^{\circ}$ chisel-point shear fracture across the thickness of the specimen. There was also a contraction in the width of the specimen at the fracture plane.

Composite specimens with low reinforcement contents of 10 to 15 vol $\%$ SiC in 6061 Al exhibited the same type of a smooth $45^{\circ}$ chisel point shear fracture across the thickness, but without the width contraction (fig. 12(a)). Failure strains of 6 to 12 percent were observed with this type of fracture. SEM photographs of 10 vol $\% \mathrm{SiC}_{\mathrm{W}} / 6061 \mathrm{Al}$ composites showed a ductile fracture with a fine lacy dimple network (fig. 13(a)). Fracture surfaces in the more ductile orientations showed a finer dimple network structure, while the dimple network structures were slightly coarser in the less-ductile direction.

At intermediate reinforcement contents (20 vol $\%)$, the failure strain was reduced to the 5 to 2 percent range, and the fracture behavior underwent a transition (fig. 12 (b)). At the higher strain portion of this range, the fracture had a $45^{\circ}$ shear lip formed at each side of the width and intersected to form a "V". At the lower strain portion of this range, a smooth $45^{\circ}$ chisel formed at one edge and extended about half-way through the width of the specimen, but then became flat and granular for the remainder of the section thickness. Fracture surfaces of composites in this intermediate reinforcement range showed a coarsening of the dimple network (fig. 13(b)).

At reinforcement contents of 30 to 40 vol \%, the fracture became flat and granular across the entire width, with no evidence of a chisel point shear lip (fig. $12(c)$ ). Composites exhibiting this type of fracture mode failed in a 
brittle manner, with a failure strain of 2 percent or less. This type of fracture showed cleavage fractures with some coarse dimple networks still visible. As the reinforcement content increased, the ductility decreased and more of the fracture surface area failed by cleavage (fig. 13(c)).

Results reported in the literature for SiC/Al composites tended to show lower failure strains than were observed in this current study. Failure strains of $<1$ to 2.5 percent for several Al matrix composites containing various SiC reinforcements, were reported in references 4,5 and 7 . However, reference 8 reported failure strains of about 4.5 percent in 20 vol \% $\mathrm{SiC}_{\mathrm{W}} / 6061$ Al composites. This increase in ductility was attributed to improved homogeneity of the $\mathrm{SiC}_{\mathrm{W}}$ reinforcement by rolling after extrusion.

The increase in failure strain observed with the SiC/Al composites tested in this current investigation can probably be attributed to two main factors. First, the fabricators of the composites are constantly striving for cleaner. more uniform Al alloy powders, and for more uniform control of fabrication variables. Cleaner, purer alloy powders can reduce the amount of impurities that can potentially form brittle intermetallics, and more uniform powders and reinforcements allow better control of powder size distribution, interparticle spacing and homogeneity of the structure. In addition, the evolutionary development of the composites also includes betler beneficiation processing to separate out debris and unwanted particles from the reinforcement. Thus, when comparing data reported for SiC/Al composites, the date that the composites were fabricated becomes important, since this helps to define the fabrication state of the art of the composites, which in turn helps determine the state of evolution of strength and ductility behavior.

The second factor affecting the improvement of the ductility of the SiC/Al composites studied in this investigation is that the composites were made from larger billets and were probably more heavily worked than most of the com-posites previously reported. The higher degree of reduction by mechanical working helps increase composite ductility in three ways: it reduces matrix porosity to a greater degree; it breaks up inclusions and more effectively stringers them; and it makes the dispersion of reinforcing particles finer and more uniform. All of these factors would have a beneficial effect on composite ductility. The SEM study showed that the particle size of the $\mathrm{SiC}_{p}$ and $\mathrm{SiC}_{n}$ reinforcements was rather coarse in comparison with the $S_{i C_{W}}$ reinforcement. Further work should be devoted to study the effects of finer particle sizes of the $S_{i C}$ and $S_{i C}$ reinforcements to see if a finer dispersion of these reinforcements could increase the strength and ductility of these composites.

\section{Elevated Temperature Properties}

Discontinuous SiC/Al composites continued to show an advantage over conventional aluminum alloys at elevated temperatures. Results of tensile tests conducted on 20 vol \% $\mathrm{SiC}_{\mathrm{W}} / 6061 \mathrm{Al}$ composites are plotted in figure 14 for temperatures up to $316^{\circ} \mathrm{C}\left(600^{\circ} \mathrm{F}\right)$. These tests were conducted by allowing the specimen to stabilize at temperature for about 10 minutes prior to test.

Specimens tested at temperatures of $149^{\circ}$ to $204^{\circ} \mathrm{C}\left(300^{\circ}\right.$ to $\left.400^{\circ} \mathrm{F}\right)$ exhibiting the same type of $V$-shaped, double shear lip transition fracture observed in tests at room temperature. Specimens tested at $260^{\circ} \mathrm{C}\left(500^{\circ} \mathrm{F}\right)$ showed a 
slight increase in plastic strain. While still transitional, the fracture showed more of a tendency for the formation of a more ductile, single shear lip and was basically the same as that observed at lower temperatures. Failure strain appeared to increase slightly at $316^{\circ} \mathrm{C}\left(600^{\circ} \mathrm{F}\right)$, however the fracture behavior changed markedly. The fracture showed a great deal of necking in both the width and thickness direction of the specimen, and all four surfaces of the fracture area necked in a ductile manner. This change in fracture behavior coincided with the marked drop in ultimate tensile strength observed at $316^{\circ} \mathrm{C}\left(600^{\circ} \mathrm{F}\right)$.

Reference 9 reported that 20 vol $\% \mathrm{SiC}_{\mathrm{W}} / 2024 \mathrm{Al}$ composites showed a similar strength advantage over unreinforced $2024 \mathrm{Al}$ at elevated temperatures. In that work, round tensile test specimens were used, thus allowing reduction in area measurements to be made at the necked fracture area. It was found that, at temperatures of less than $240^{\circ} \mathrm{C}\left(460^{\circ} \mathrm{F}\right)$, the composites failed with relatively little plastic flow and no necking. At $240^{\circ} \mathrm{C}\left(460^{\circ} \mathrm{F}\right)$, the composites showed an abrupt change in behavior and exhibited significant necking and failed at plastic strains of about 10 percent. Further tests at temperatures up to about $400^{\circ} \mathrm{C}\left(752^{\circ} \mathrm{F}\right)$ showed similar behavior.

The results obtained in this investigation, as well as those results reported in reference 9 , show that SiC/Al composites offer about a $117^{\circ} \mathrm{C}$ $\left(200^{\circ} \mathrm{F}\right)$ increase in use temperature over conventional aluminum alloys. The results also indicate that $\mathrm{SiC/Al}$ composites can be used effectively at temperatures up to at least $204^{\circ} \mathrm{C}\left(400^{\circ} \mathrm{F}\right)$

\section{Application of SiC/Al Composites to Aircraft Engine and Aerospace Structures}

The results of this study showed that these low cost SiC/Al matrix composites, currently projected to sell for about $\$ 20 / 1 \mathrm{~b}$, demonstrated a good potential for application to aerospace structures and aircraft engine components. The composites are formable with normal aluminum metalworking techniques and equipment at warm working temperatures. They can also be made directly into structural shapes during fabricalion. These composites merit additional work to determine fatigue, long-term stability, and thermal cycle behavior to more fully characterize their properties and allow their consideration for structural design for a variety of aircraft and spacecraft applications.

The most significant aspect of these data was the increase in modulus over that of competitive aluminum alloys. At 20 vol $\%$ reinforcement, the modulus of SiC/Al composites was about 50 percent above that of aluminum and approached that of titanium. This increase in modulus was achieved with a material having a density one-third less than that of titanium. Comparison of the properties of the various composites tested in this study (fig. 15) shows that the modulus/density ratio of $20 \mathrm{vol} \% \mathrm{SiC} / \mathrm{Al}$ composites was about 50 percent greater than that of $A l$ or Ti alloys, while at 30 vol \% SiC the advantage was increased to about 70 percent, and at 40 vol \% SiC the modulus was almost double that of unreinforced $\mathrm{Al}$ or Ti structural alloys.

The Boeing Co. has reported (ref. 10) that it expects to save about 10 percent of the structural weight of advanced transports, currently under design, through the use of new Al-Li alloys. The results obtained in this 
current study showed that discontinuous SiC/Al composites offered significantly better modulus, modulus/density, and ductility properties than do the AT-Li alloys reported in references 11 and 12 . The SiC/Al composites had about the same yield and ultimate tensile strengths and so the use of these SiC/Al composites could save appreciably more weight in airframe and engine structures, and offer the potential to reduce aircraft weight by possibly as much as twice that projected when using the Al-Li alloys.

\section{CONCLUSIONS}

Studies were undertaken to evaluate the tensile behavior of low-cost discontinuous SiC/Al composites, containing SiC-whisker, -nodule, or -particulate reinforcement. The effects of reinforcement type, matrix alloy, reinforcement content, and orientation were determined by analysis of stress-strain curves and by SEM examination. This investigation led to the following conclusions:

(1) Discontinuous SiC/Al composites offer a 50 to 100 percent increase over the modulus of unreinforced aluminum and offer a modulus equivalent to that of titanium, but at a third less density. The Sic/Al composites had modulus/density ratios of up to almost twice those of titanium and aluminum structural alloys. The modulus of SiC/Al composites tended to be isotropic and was controlled by the amount of Sic reinforcement.

(2) The yield and tensile strengths of SiC/Al composites demonstrated up to a 60 percent increase over those of the unreinforced matrix alloys. Yield and ultimate tensile strengths of the composites were controlled by the type and temper of the matrix alloy, and by reinforcement content. In general, these properties were independent of the type of reinforcement. This suggests that, with the present state of the art of materials and fabrication, $\mathrm{sic}_{\mathrm{p}}$ or $\mathrm{SiC}_{n}$ reinforcements appear equally effective as SiC-whiskers.

(3) Ductility of SiC/Al composites, as measured by strain to failure, was dependent upon reinforcement content and matrix alloy. Composites with ductile matrix alloys and lower reinforcement contents exhibited a ductile shear fracture with a 5 to 12 percent failure strain. As reinforcement content increased, the fracture progressed through a transition and became brittle, reaching a $<1$ to 2 percent failure strain, at higher reinforcement contents. The increase in ductility over that reported previously was attributed to cleaner matrix alloy powders and increased mechanical working.

(4) A fine dimple network was observed in the fracture surfaces of composites with higher strains. At lower fracture strains, a coarser dimple network was observed. Composites failing in a brittle manner showed increasing amounts of cleavage fracture.

(5) The SiC-whisker reinforcement was generally oriented in the extrusion direction. Composites with a higher degree of preferred orientation tended to have higher ultimate tensile strength in the direction of whisker orientation. Composites with a more random whisker orientation tended to be isotropic in strength. 


\section{REFERENCES}

1. D. L. McDanels and R. A. Signorelli: NASA TM-83357, NASA Lewis Research Center, Cleveland, $\mathrm{OH}, 1983$.

2. D. L. McDanels and C. A. Hoffman: NASA TP-2302, NASA Lewis Research Center, Cleveland, $\mathrm{OH}, 1984$.

3. B. C. Bechtold, R. L. Beatty, and J. L. Cook: Progress in Science and Engineering of Composites, vol. 1, pp. 113-120, Japan Society for Composite Materials, Tokyo, 1982.

4. W. C. Harrigan, Jr., A. M. Nowitzky, and E. C. Supan: DWA-600, DWA Composite Specialties, Inc., Chatsworth, CA, Feb. 1982.

5. H. J. Rack, J. L. Cook, and T. R. Baruch: Progress in Science and Engineering of Composites, vo1. 2, pp. 1465-1472, Japan Society for Composite Materials, Tokyo, 1982.

6. Metals Handbook, 8th ed., vol. 1, American Society for Metals, Metals Park, OH, 1961.

7. A. P. Divecha, S. G. Fishman, and S. D. Karmarkar: J. Met., 1981, vol. 33, no. 9, pp. 12-17.

8. T. G. Nieh and R. F. Karlak: J. Mater. Sci. Lett., 1983, vol. 2, pp. 119-12?.

9. W. L. Phillips: ICCM/2; Proceedings of the 1978 International Conference on Composite Materials, pp. 567-576, Metallurgical Society of the AIME, Warrendale, PA, 1978.

10. Avia. Week Space Technol., 1983, vol. 118, no. 23, pp. 29-32.

11. T. H. Sanders, Jr.: NADC-76397-30, Naval Air Development Center, Warminster, PA, June 1976.

12. E. A. Starke, Jr., T. H. Sanders, Jr., and I. G. Palmer: J. Met., 1981 , vol. 33 , no. 8,1981, pp. 24-33. 


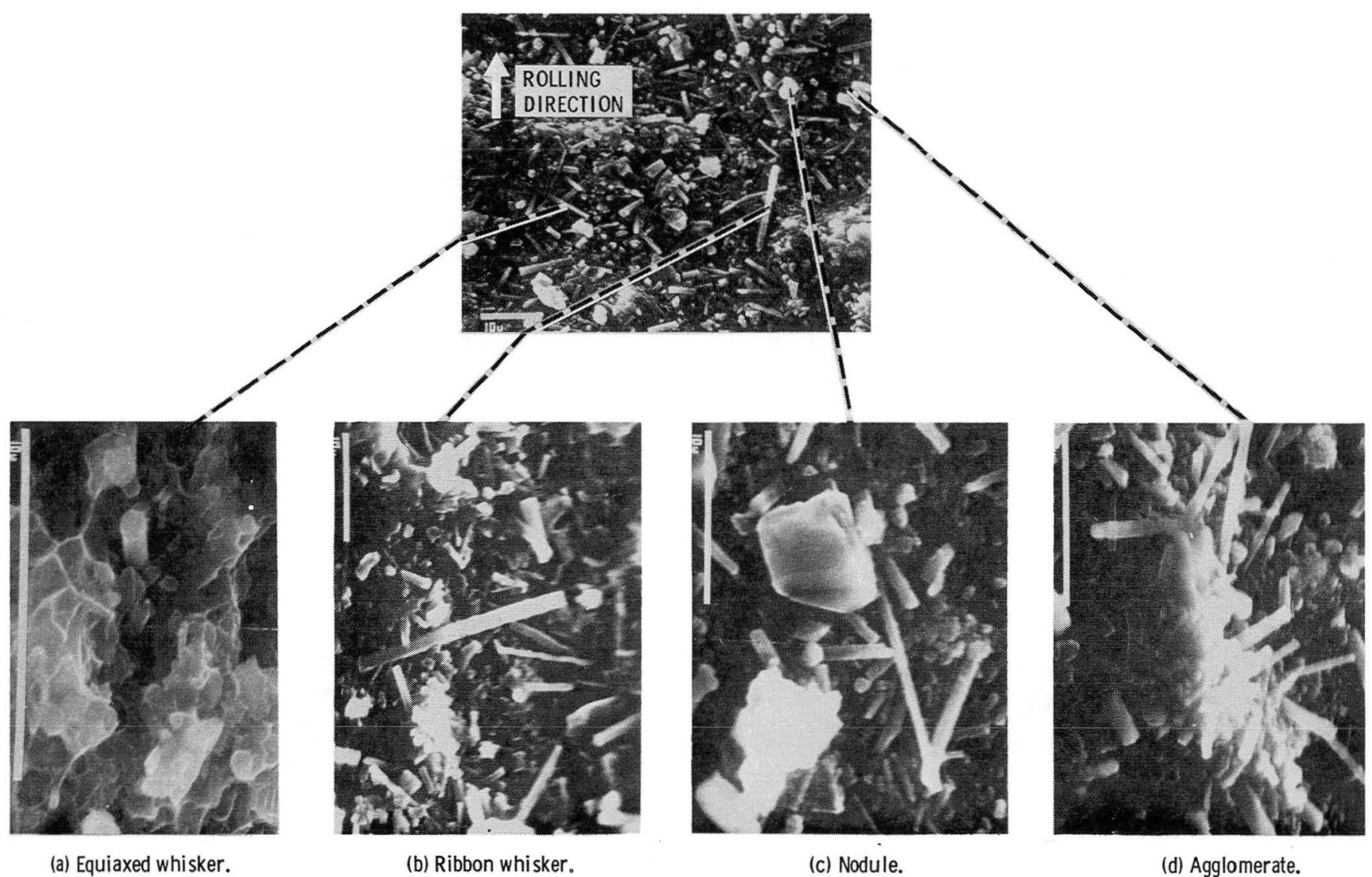

Figure 1. - Structure of etched $\mathrm{SiC}_{\mathrm{W}} / 6061$ Al composites. 


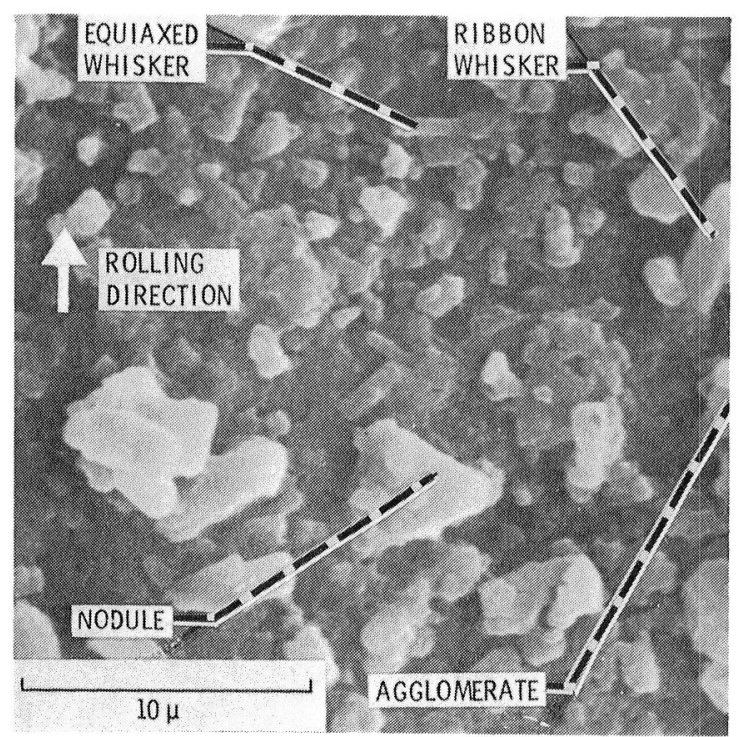

Figure 2. - Structure of etched $\mathrm{SiC}_{\mathrm{n}} / 606 \mathrm{l}$ Al composites.

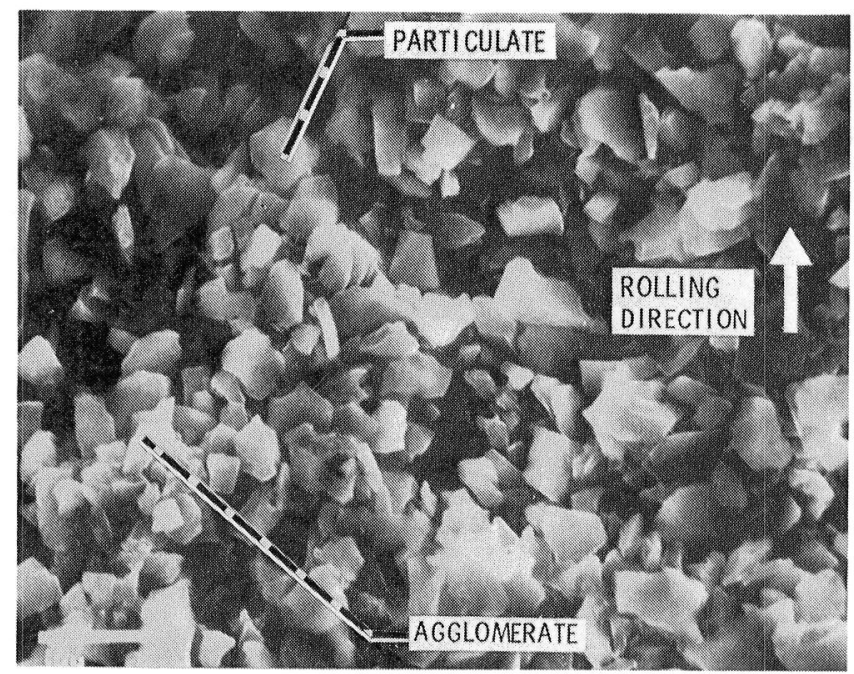

Figure 3. - Structure of etched $\mathrm{SiC}_{\mathrm{p}} / 6061 \mathrm{Al}$ composites. 


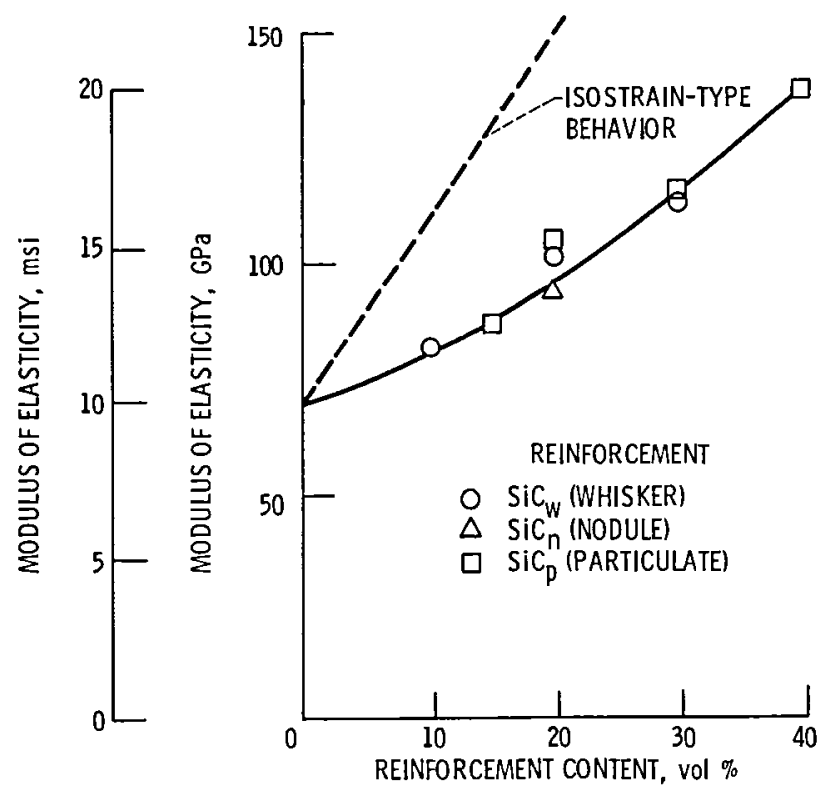

Figure 4. - Effect of reinforcement content on modulus of elasticity of discontinuous $\mathrm{SiC} / 606 \mathrm{l}$ Al composites.

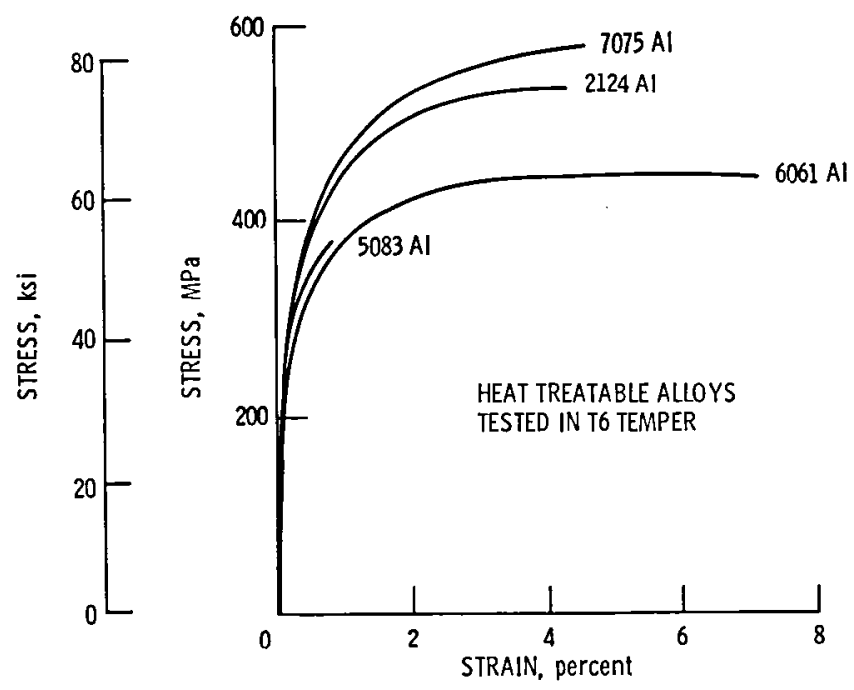

Figure 5. - Effect of Al matrix alloy on stress-strain behavior of composites with $20 \mathrm{vol} \% \mathrm{SiC}$ reinforcement. (Tested in direction parallel to final rolling direction.) 


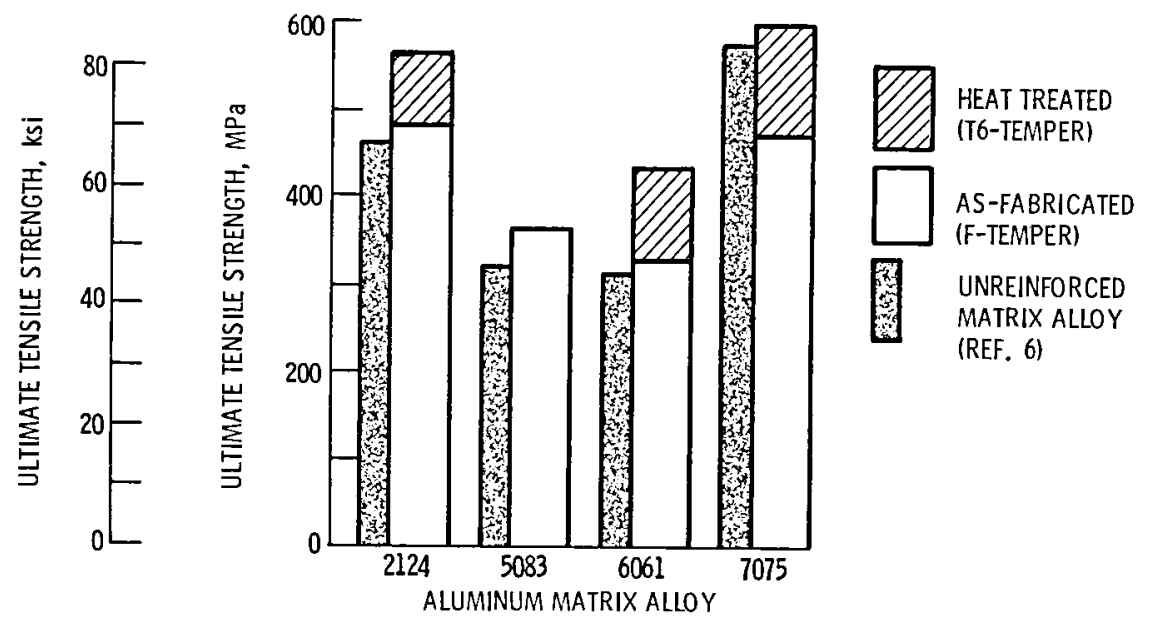

Figure 6. - Effect of matrix alloy and heat treatment on ultimate tensile strength of $20 \mathrm{vol} \% \mathrm{SiC}_{\mathrm{w}} / \mathrm{Al}$ composites.

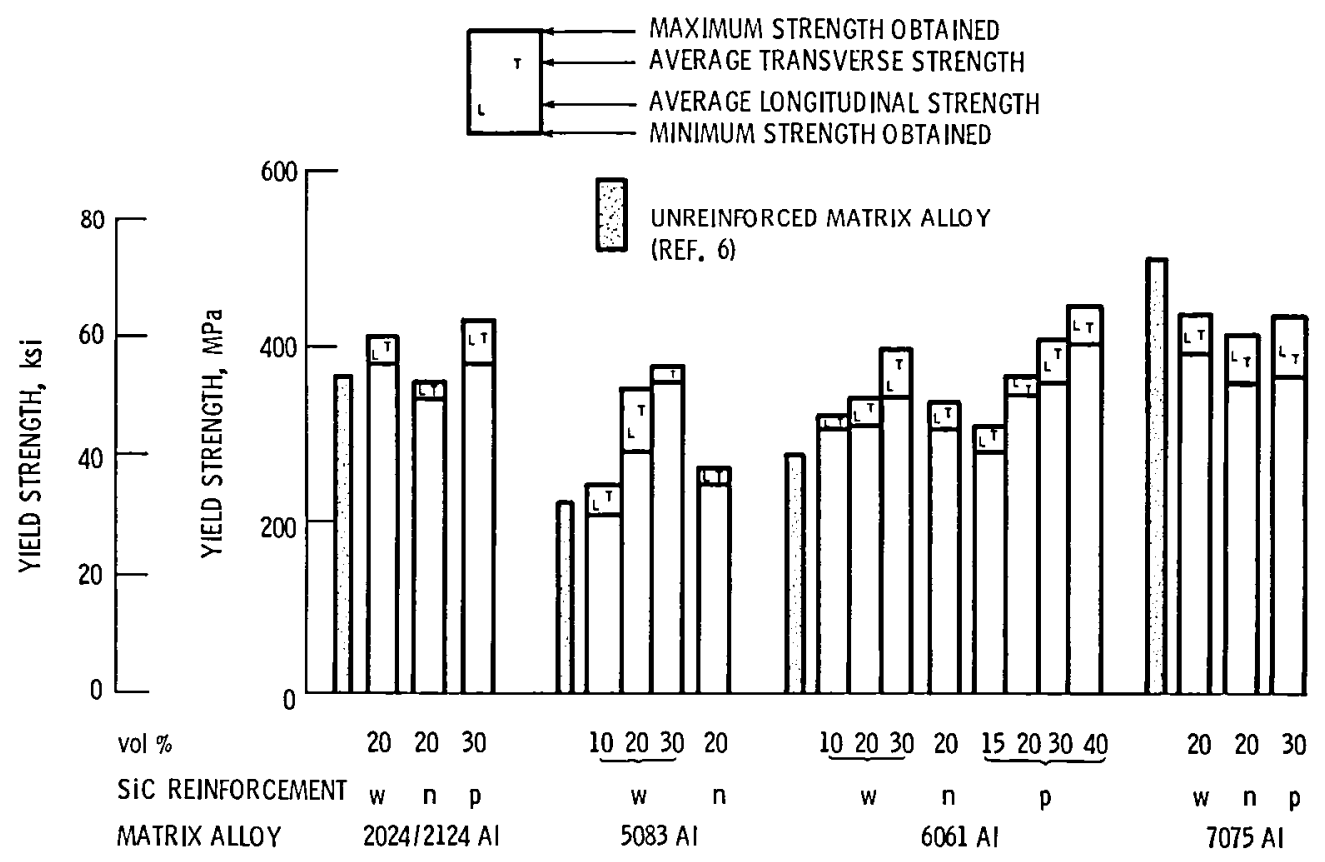

(a) 0.2 Percent offset yield strength.

Figure 7. - Effect of SiC reinforcement type and content on tensile properties of discontinuous SiC/AI composites. 


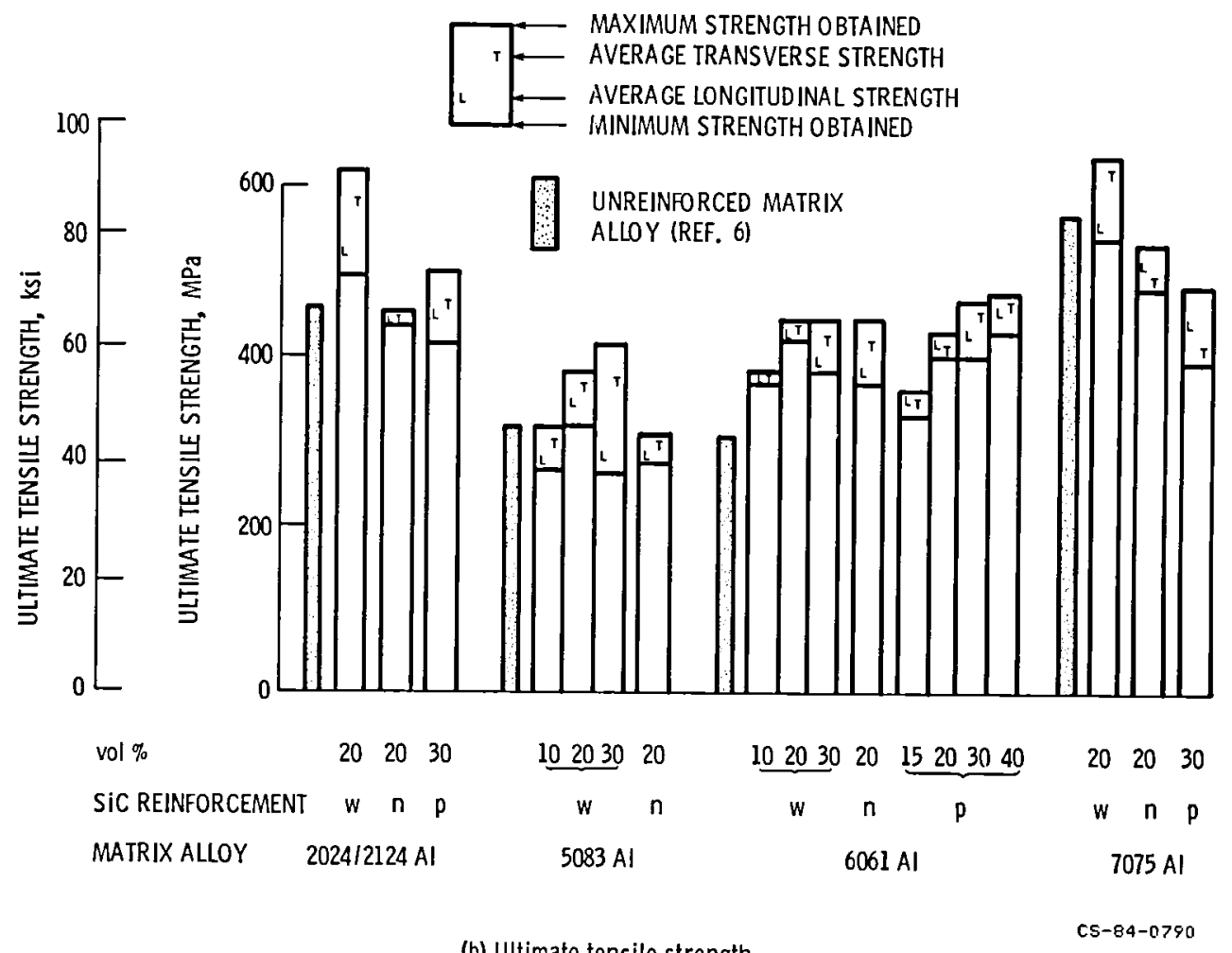

(b) Ultimate tensile strength.

Figure 7. - Concluded.

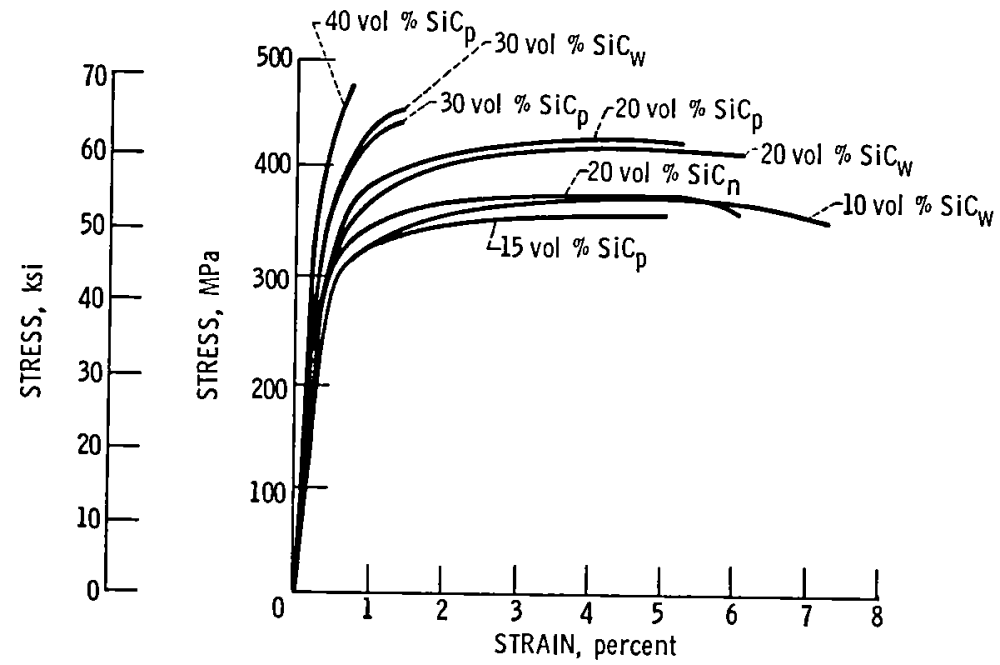

Figure 8. - Stress-strain curves of SiC 16061 Al composites. (T6-temper, tested in longitudinal direction.) 


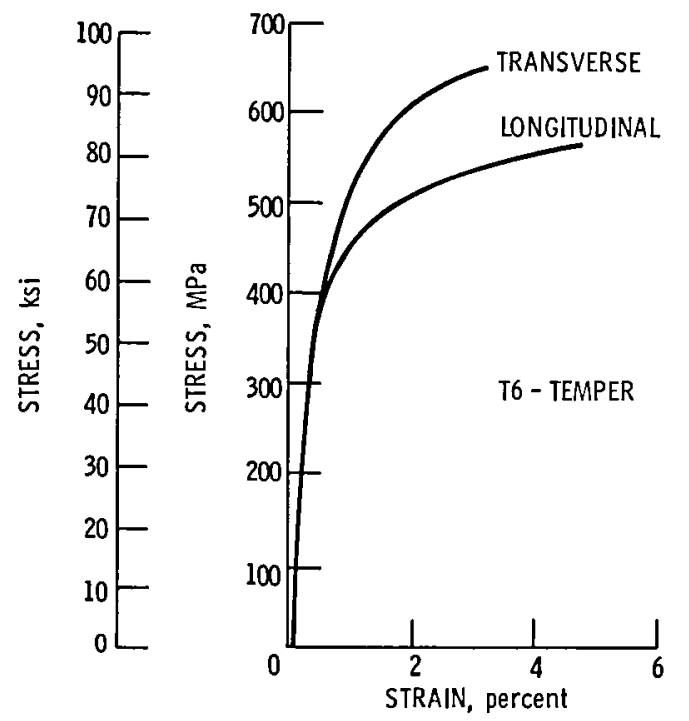

Figure 9. - Stress-strain curves of $20 \mathrm{vol} \% \mathrm{SiC}_{\mathrm{w}} l$ $7075 \mathrm{Al}$ composites tested in transverse and longitudinal orientations. 


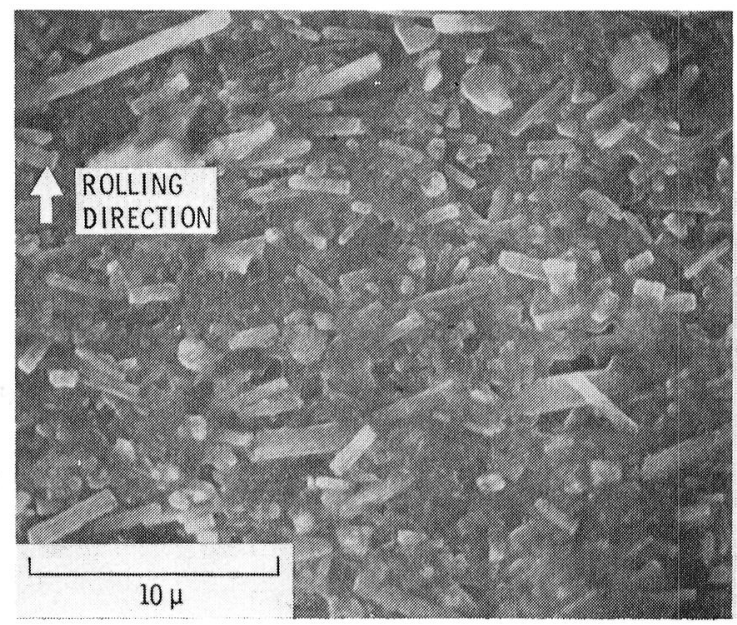

(a) General structure of etched top surface.

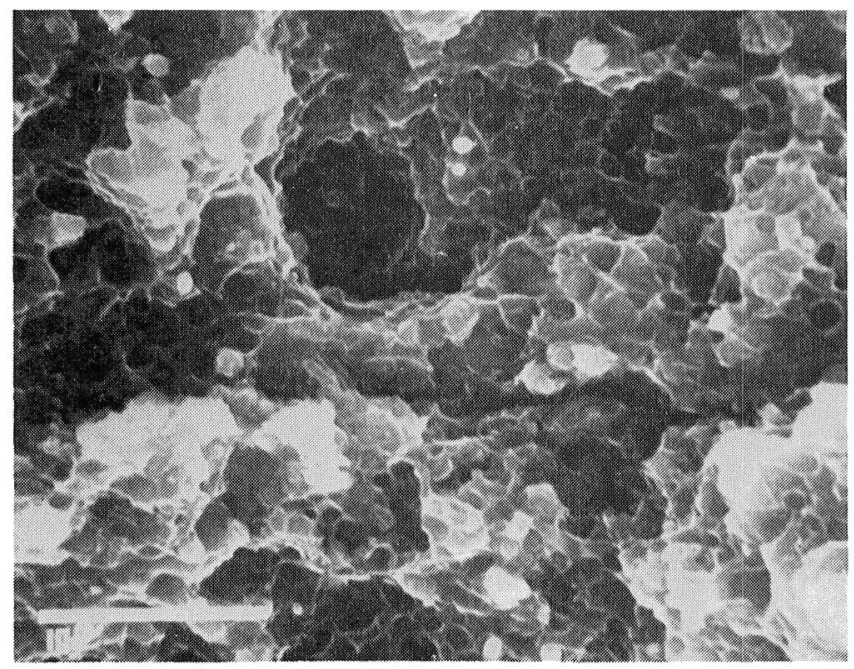

(b) Transverse orientation fracture edge.

Figure 10. - SEM photographs of $20 \mathrm{vol} \% \mathrm{SiC}_{\mathrm{w}} / 7075 \mathrm{Al}$ composites (T6 temper). 


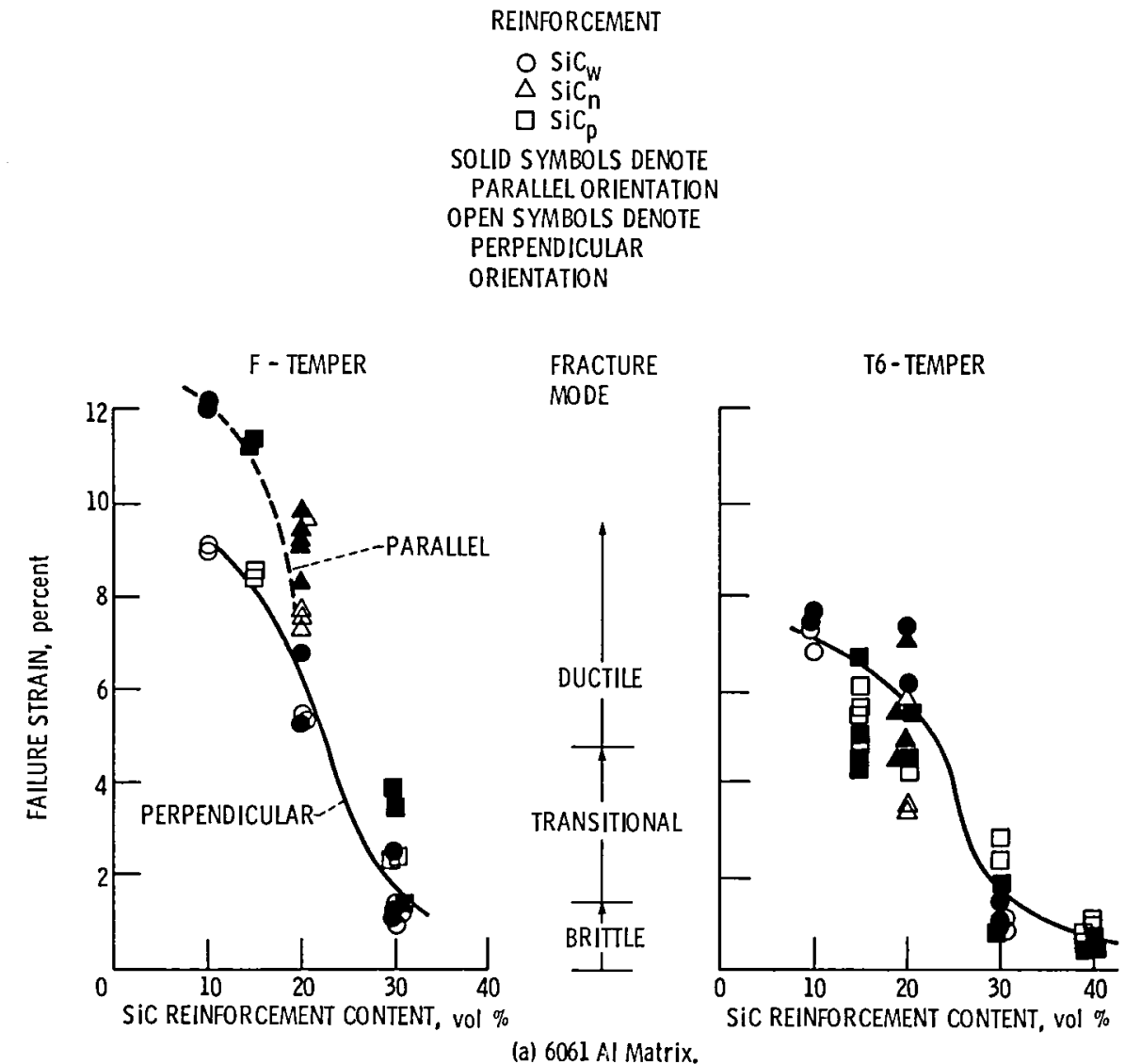

Figure 11. - Failure strain of SiCIAl composites.

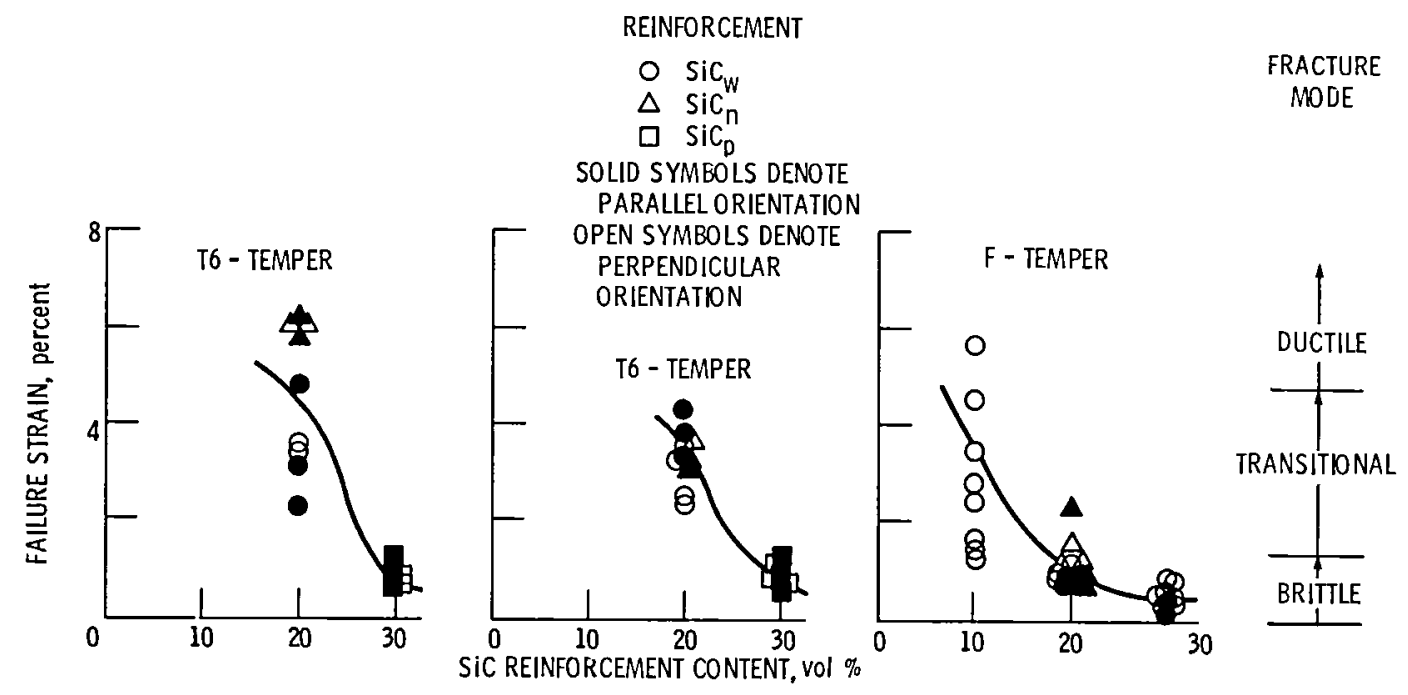

(b) 7075 Al Matrix.

(c) 2024/2124 Al Matrix.

(d) 5083 Al Matrix.

Figure 11. - Concluded. 


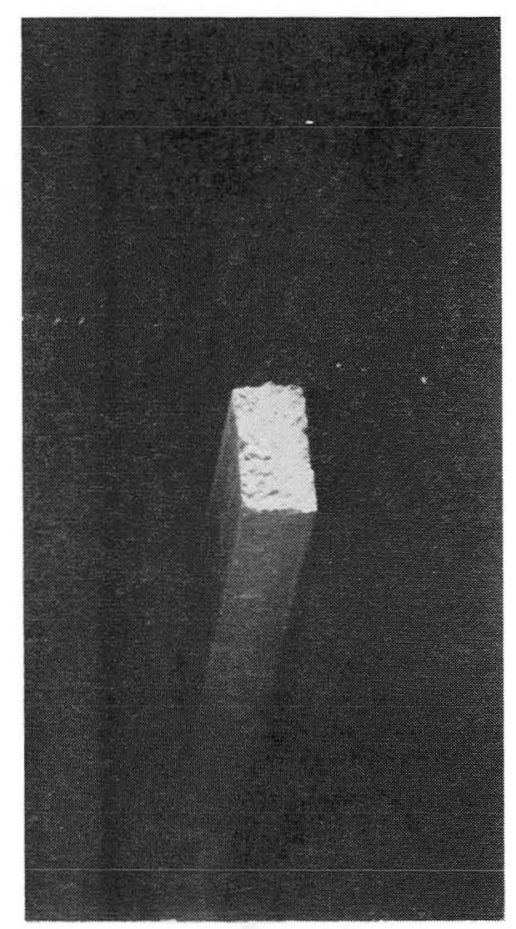

(a) Brittle.

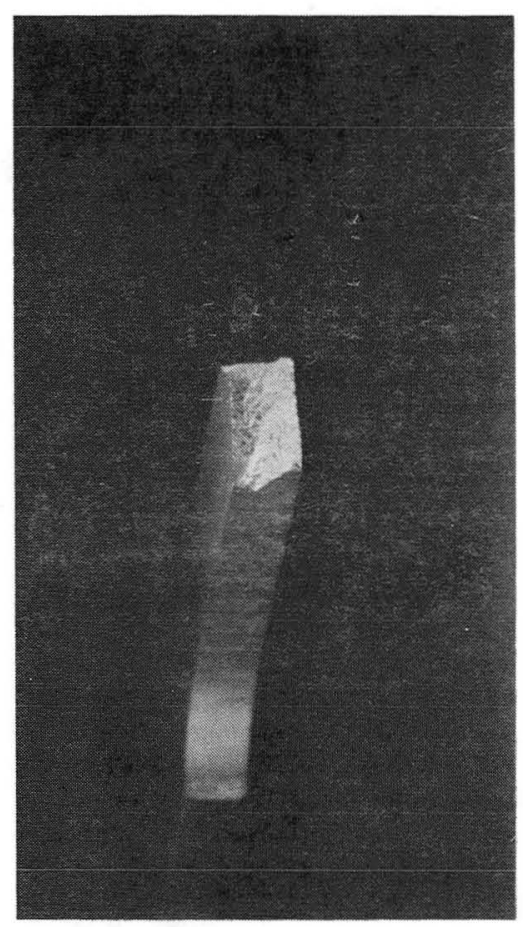

(b) Transitional.

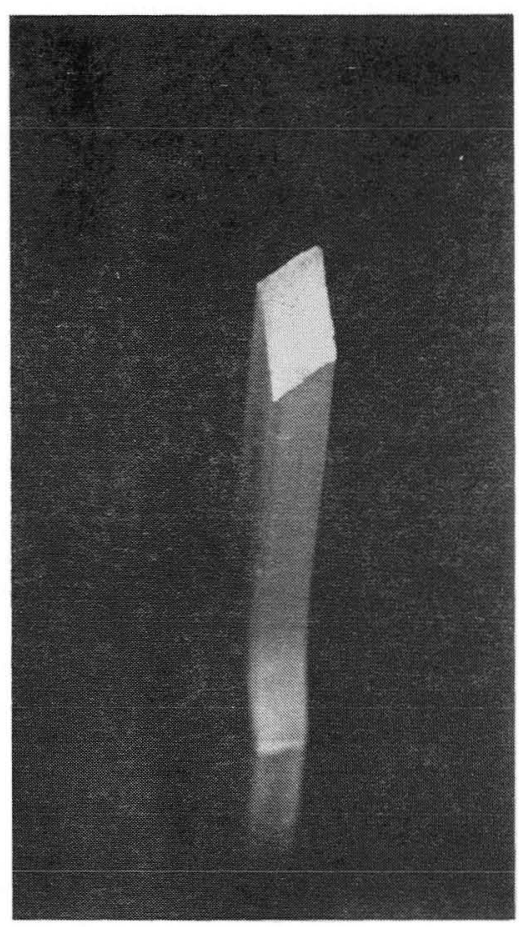

(c) Ductile.

Figure 12. - Fracture modes of SiC/AI composites. Range of failure strains; (a) brittle flat, 0 to $2 \%$; (b) transitional, 2 to $5 \%$; (c) ductile chisel, $>5 \%$. 


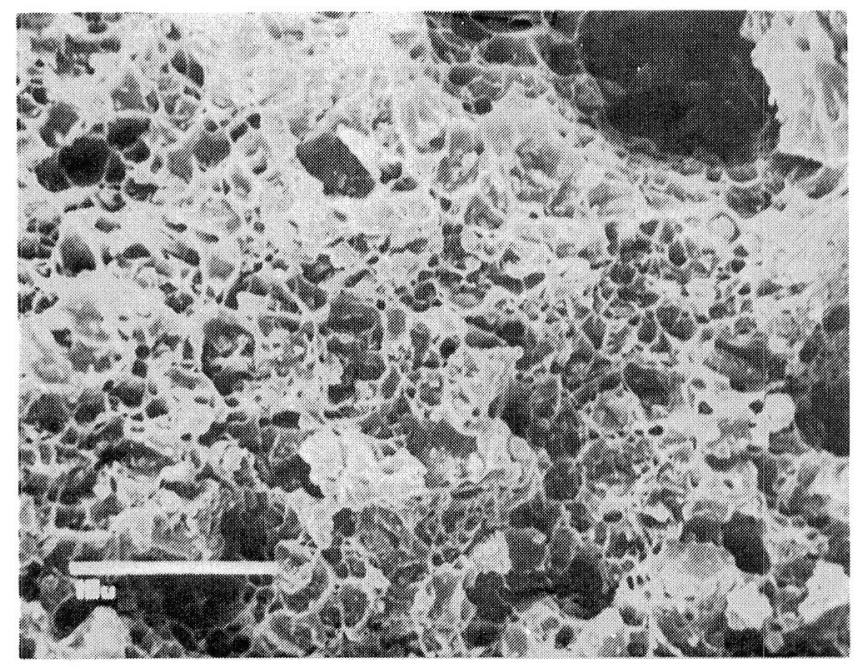

(a) 10 vol $\% \mathrm{SiC}_{\mathrm{w}} / 6061 \mathrm{Al}, \varepsilon_{\mathrm{f}}=12.0 \%$.

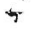

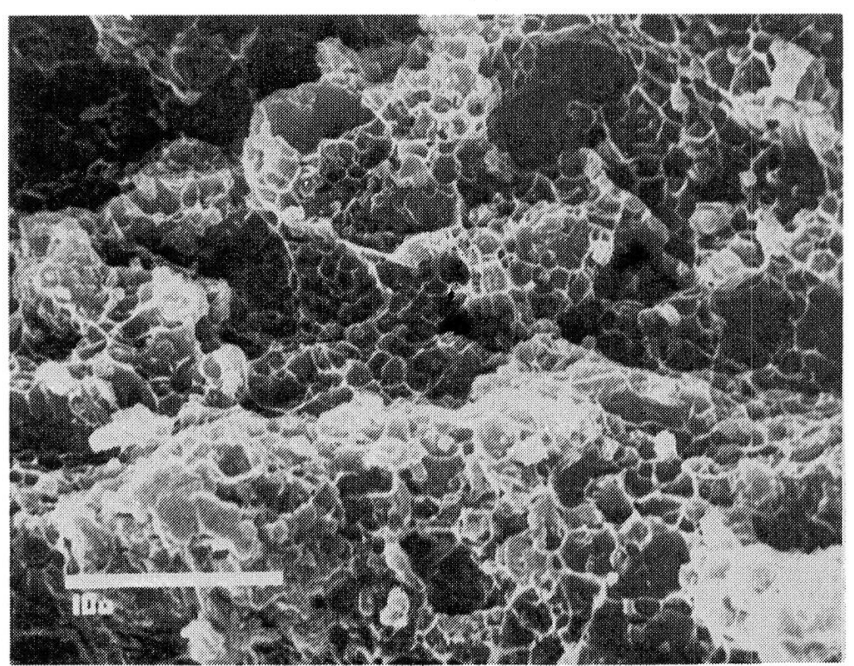

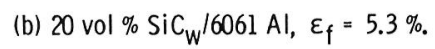

Figure 13. - Fracture surfaces of $\mathrm{SiC}_{\mathrm{w}} / 606 \mathrm{Al}$ composites (tested in longitudinal orientation). 


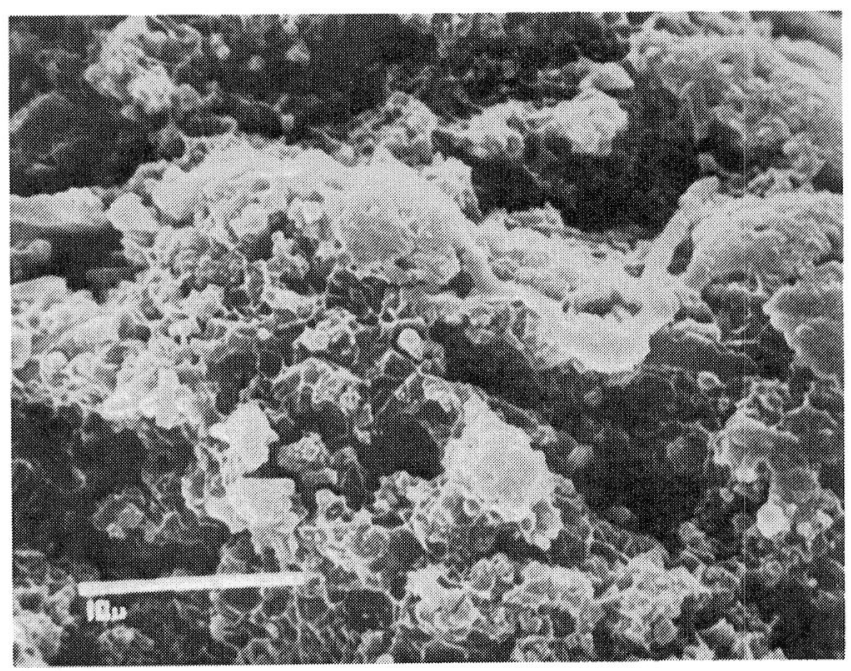

(c) 30 vol \% SiC $\mathrm{w} / 6061 \mathrm{Al}, \varepsilon_{\mathrm{f}}=2.6 \%$.

Figure 13. - Concluded.

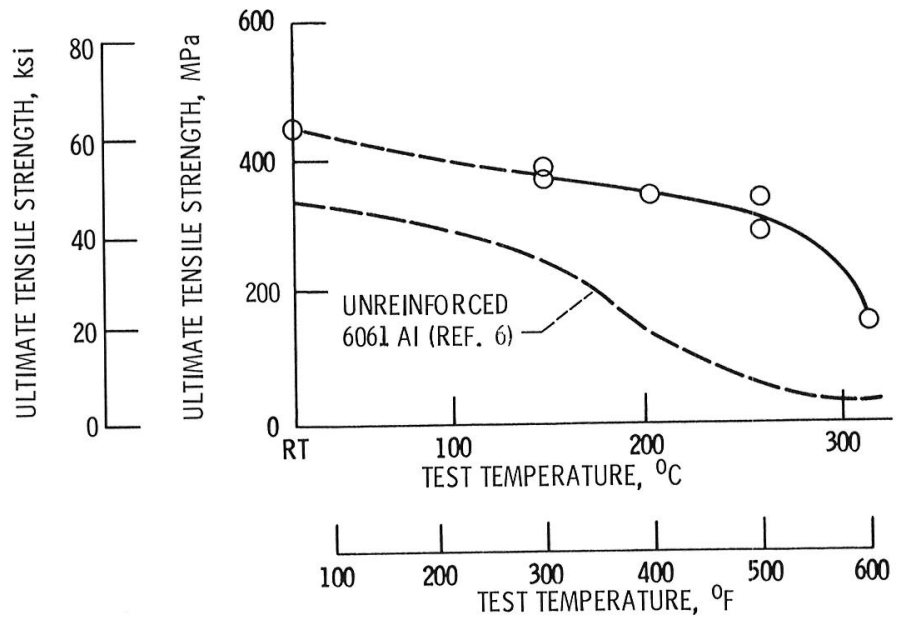

Figure 14. - Effect of test temperature on tensile strength of $20 \mathrm{vol} \%$ $\mathrm{SiC}_{\mathrm{W}} / 6061$ Al composites. 


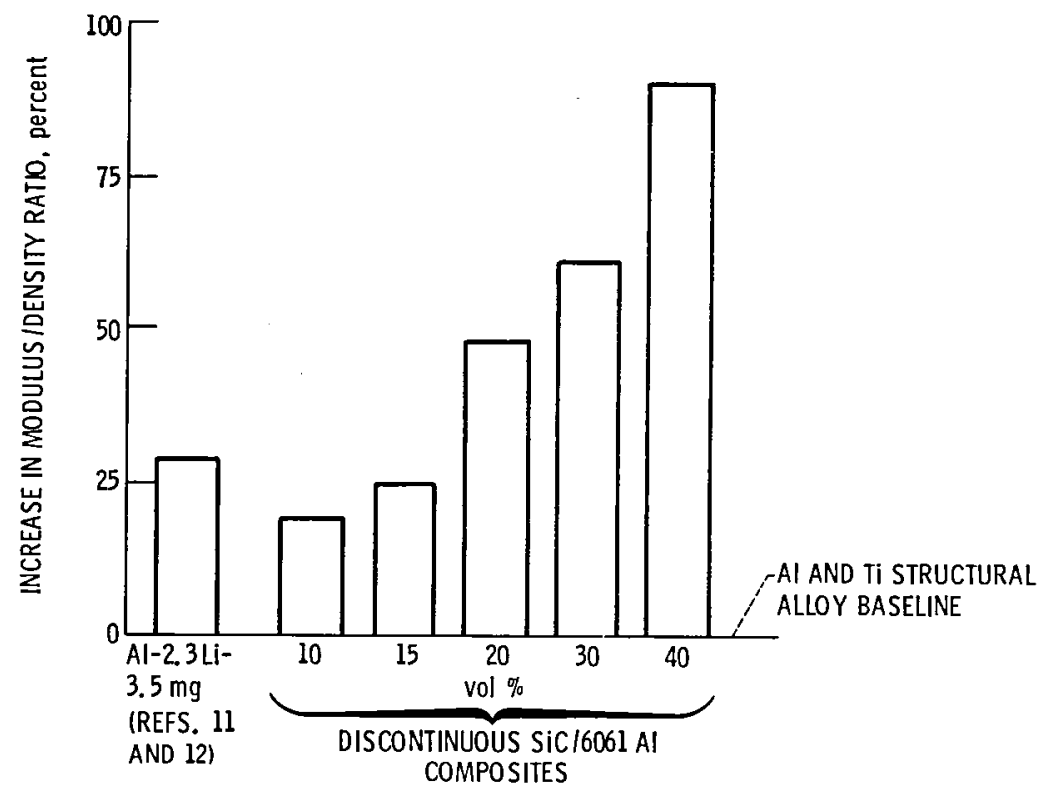

Figure 15. - Comparison of increase of modulus/density ratio of SiC/AI composites and AI-Li-mg alloy. 


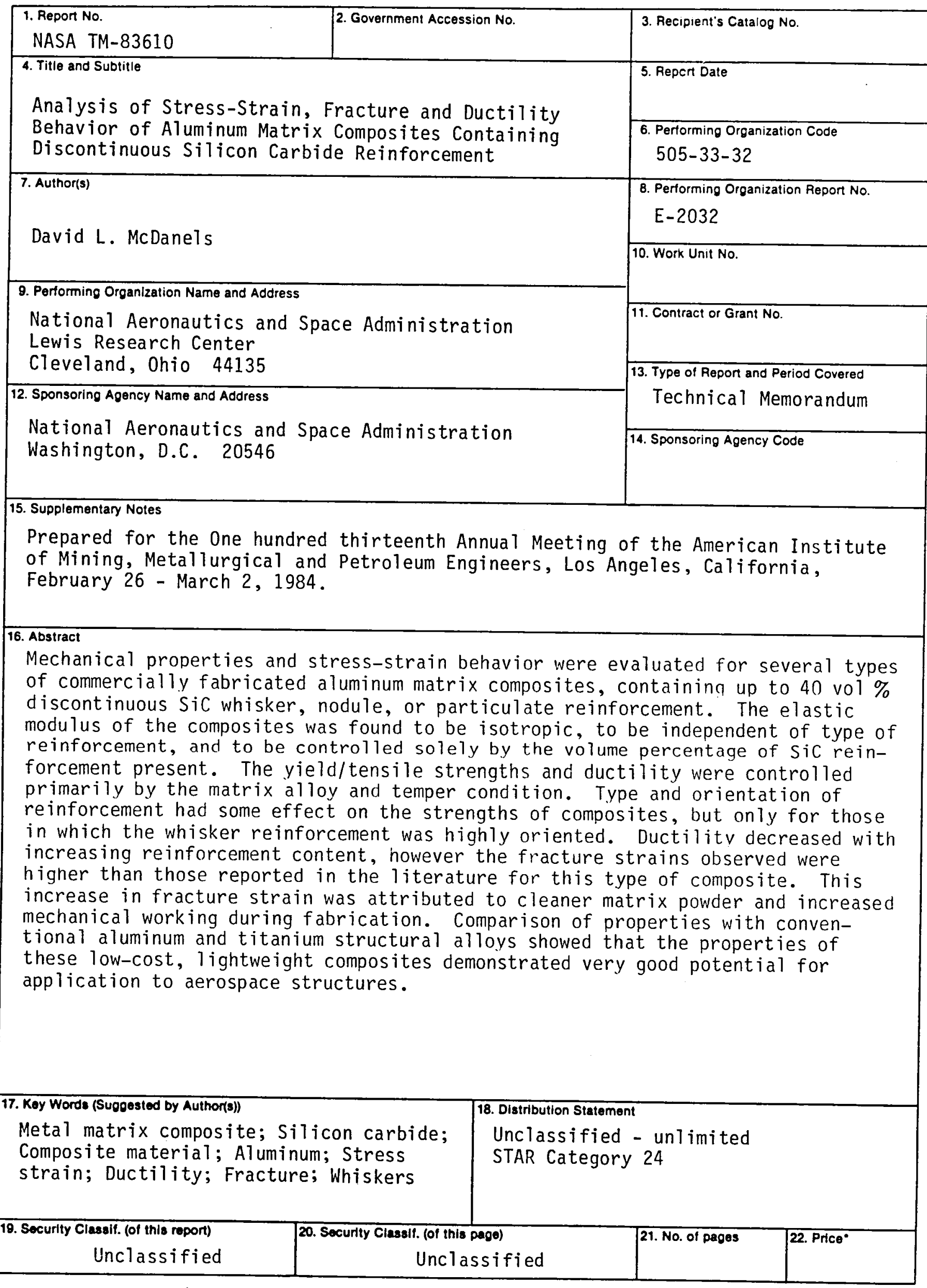

"For sale by the National Technical Information Service, Springfield, Virginia 22161 
National Aeronautics and Space Administration

Washington, D:C.

20546

Official Business

Penalty for Private Use, $\$ 300$ SPECIAL FOURTH CLASSMAIL,
BOOK

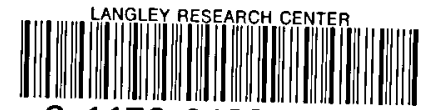

31176013258158

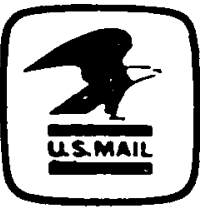

Postage and Fees Paid

National Aeronautics and

Space Administration NASA-451 